\title{
LOS AGITADOS MINUTOS DE UN PRESIDENTE ELECTO: ALLENDE CONVERSÓ CON "CLARIDAD”"
}

\section{Revista Claridad}

Claridad fue la revista oficial de la Federación de Estudiantes de la Universidad de Chile y un órgano fundamental de expresión crítica y social de la generación de jóvenes universitarios de 1920, que se destacó por la radicalización ideológica y su compromiso político con las demandas de la clase obrera.

Tiene varias etapas de existencia. La primera abarcó desde 1920 hasta la dictadura de Carlos Ibáñez del Campo en 1926, para reaparecer entre 1930 y 1932. En las siguientes décadas del siglo XX la revista se reeditó de manera irregular. Este número fue publicado en noviembre de 1970, a pocos días de que Salvador Allende (médico cirujano egresado de la Escuela de Medicina de la Universidad de Chile) fuera proclamado presidente de la república por el Congreso Nacional.

Con ánimo cordial y esperanzador, Claridad recalca el compromiso de los estudiantes por "construir y defender el Chile Nuevo". Las páginas que aquí seleccionamos corresponden a una breve entrevista realizada al presidente Allende por el equipo editorial de la revista, en su casa personal ubicada en la calle Guardia Vieja de la comuna de Providencia, en Santiago.

En este reportaje, Claridad destaca un reportaje gráfico que tiene como centro la participación de los estudiantes y de las mujeres en particular como agentes fundamentales del triunfo de su campaña. En la fotografía principal aparece Lily Corvalán, directora de la revista. Un punto interesante de la conversación es cuando se le pregunta al presidente Allende por qué escogió dar el saludo el día de la victoria electoral (4 de septiembre de 1970) desde la terraza del local de la FECH, ubicado en Alameda 1346 (hoy sede de la CUT). A la pregunta responde que la relación entre universidad y verdad era de correspondencia, y que la verdad era que la nueva sociedad era un proyecto que sin la juventud era irrealizable.

1. Claridad (1970, noviembre). Federación de Estudiantes de la Universidad de Chile, pp. 6-7. Disponible en: http:/ /www.memoriachilena.gob.cl/602/w3-article-546421.html 


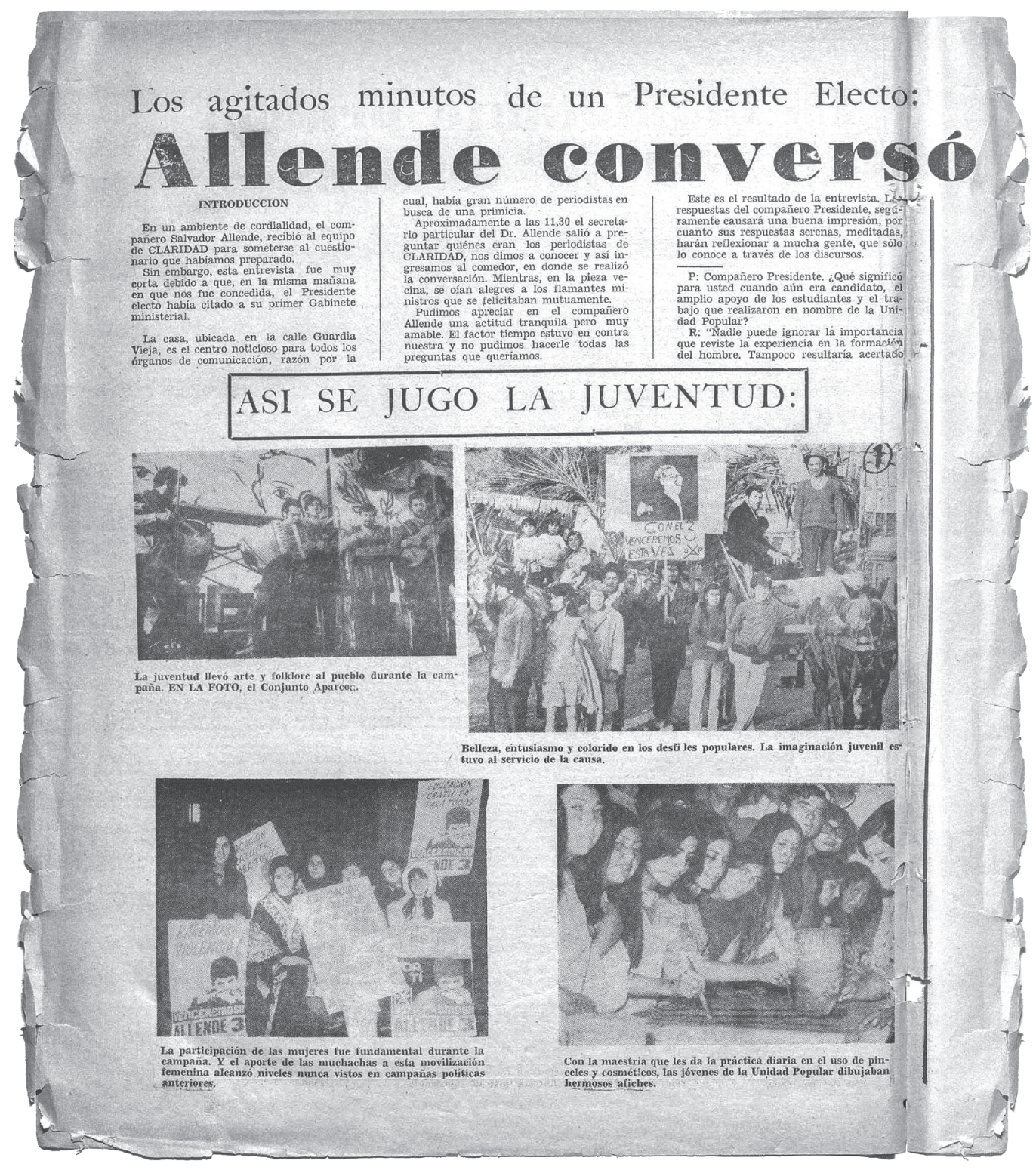




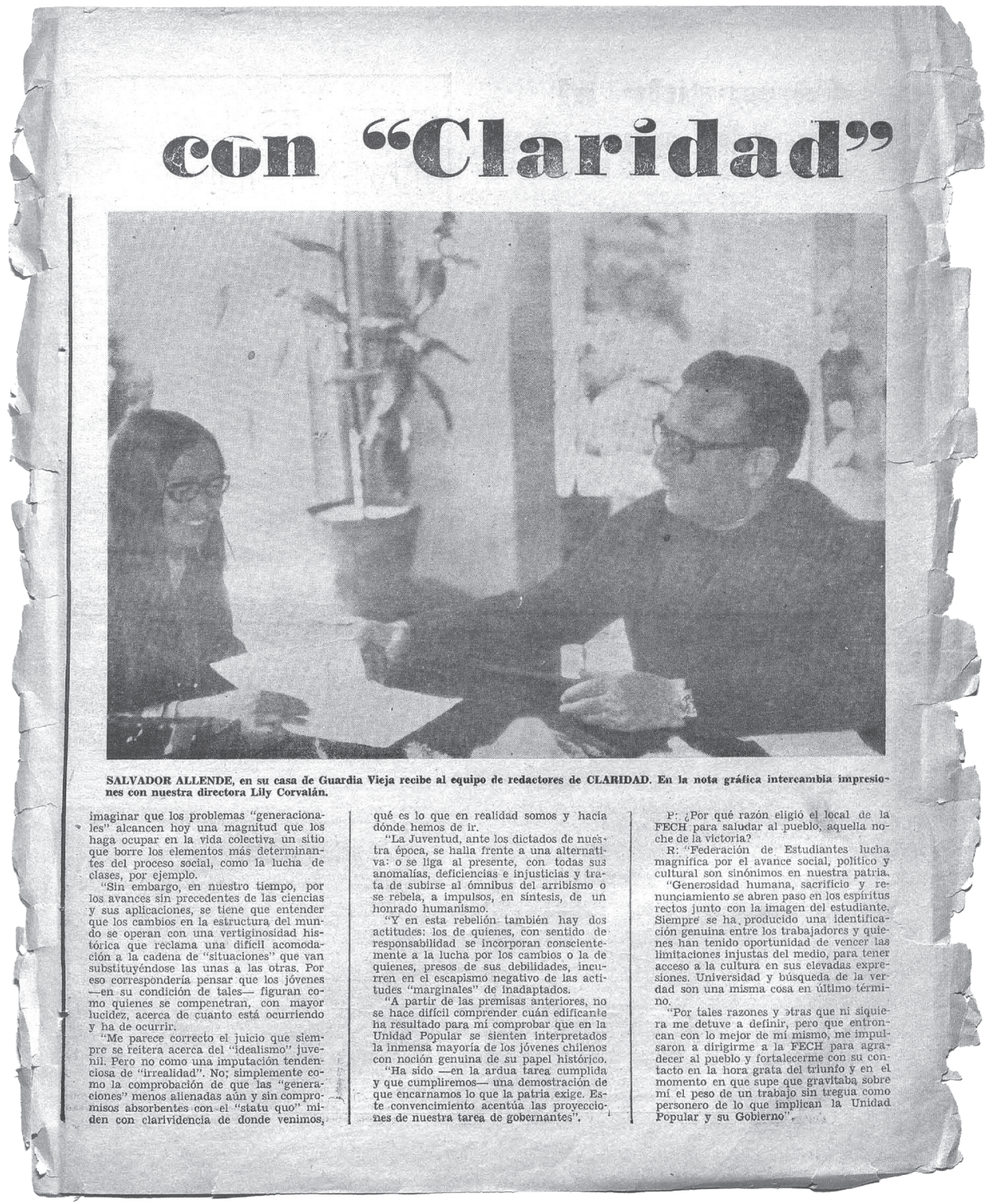

